\title{
Mitigação dos Efeitos das Mudanças Climáticas a partir da Substituição Gradual de Termelétricas a Carvão por Usinas Fotovoltaicas
}

\author{
Larissa Mendes Rodrigues ${ }^{1}$ (D), Marcos Antonio Tavares Lira $^{2}$ (D), \\ Miguel Leocádio de Sousa Neto ${ }^{2}$ \\ ${ }^{1}$ Mestrado em Climatologia e Aplicações nos Países da CPLP, Universidade Estadual do Ceará, \\ Fortaleza, CE, Brasil. \\ ${ }^{2}$ Departamento de Engenharia Elétrica, Universidade Federal do Piauí, Teresina, PI, Brasil.
}

Recebido em: 13 de Abril de 2020 - Aceito em: 1 de Junho de 2020

\begin{abstract}
Resumo
O presente trabalho foca na redução da emissão de gases de efeito estufa e do volume de água captado no processo de geração de energia nas termelétricas que utilizam o carvão mineral e intensificam a crise hídrica em regiões do semiárido brasileiro. O estudo foi feito em uma das maiores usinas a carvão do Brasil, a Energia Pecém, situada no Porto do Pecém, no Estado do Ceará, selecionando-se a unidade Pecém II. Propõe-se o desligamento dessa unidade durante sete horas por dia a partir da operação de uma usina fotovoltaica de grande porte instalada em áreas classificadas como em processo de desertificação no estado, especificamente no município de Irauçuba, com a mesma capacidade de geração da termelétrica em questão. Para isso, foi desenvolvido um projeto preliminar de usina fotovoltaica, cuja viabilidade técnica, econômica e ambiental foi avaliada. Dessa forma, estima-se uma queda na emissão do dióxido de carbono em torno de 34.720,56 toneladas por mês e na captação de água uma redução de 9,67\% do seu volume mensal.
\end{abstract}

Palavras-chave: gases de efeito estufa, energia elétrica, captação de água.

\section{Mitigation of the Effects of Climate Change from the Gradual Replacement of Coal Thermal Power Stations by Photovoltaic Plants}

\begin{abstract}
This paper focuses on reducing the emission of greenhouse gases and the volume of water captured in the energy generation process in thermoelectric plants thar use mineral coal and intensify the water crisis in regions of the Brazilian semiarid. The study was made in the largest coal-fired power plant in Brazil, Energia Pecém, located in Porto do Pecém, in the state of Ceará, taking unit Pecém II. Is is proposed to shut down this unit for seven hours a day from the operation of a large photovoltaic plant installed in áreas classified as desert in the state, specifically in the municipality of Irauçuba, with the same generation as that thermoelectric plant. For this, a preliminar project of a photovoltaic plant was made, whose technical, economic and environmental feasibility was assessed. Thus, it is estimated a drop in carbono dioxide emission of around 34,720.56 tons per month and in water abstraction a reduction of $9.67 \%$ of its monthly volume.
\end{abstract}

Keywords: greenhouse gases, electricity, water catchment.

\section{Introdução}

Segundo o Painel Intergovernamental sobre Mudanças do Clima (IPCC), as mudanças climáticas vêm sendo aceleradas pelas atividades humanas, as quais aumentam a emissão de gases tóxicos e poluentes (IPCC, 2013). Dentre esses gases poluentes, os mais preocupantes são os Gases do Efeito Estufa (GEE), que possuem uma grande capacidade de reter a radiação terrestre e solar (Oliveira, 2009; Nascimento, 2016; Drumm, 2014).

Autor de correspondência: Miguel Leocádio de Sousa Neto, miguel@ufpi.edu.br. 
A seca prolongada em alguns estados da região nordeste do Brasil é um dos impactos das mudanças climáticas que afeta o volume dos reservatórios locais que atendem o abastecimento humano, as indústrias, a irrigação e algumas fontes de geração de energia. As atividades antrópicas têm aumentado a concentração de GEE ao longo das últimas décadas e, no Brasil, a maior parte das emissões é oriunda de setores ligados à geração de energia elétrica (Tilio Neto, 2010). A geração hidráulica da região Nordeste no ano de 2017 teve um recuo de $70 \%$ da potência fornecida em relação à potência máxima registrada no período de 2000 a 2017 (ONS, 2017). Para suprir a demanda de energia, em caráter emergencial, entraram em operação muitas termelétricas que, além de utilizar, em sua maioria, combustíveis poluentes, demandam grandes volumes de água em seu processo de geração de energia elétrica. Assim, com a operação das termelétricas, além do aumento da emissão de GEE, a situação hídrica se agravou em alguns estados, em particular no Ceará.

Existe uma contradição alarmante no contexto hídrico e ambiental do Ceará: a região possui mais de $80 \%$ do seu território no semiárido e em situação crítica devido a uma seca prolongada desde 2012. Paralelamente, o estado se destaca por possuir umas das maiores e mais poluentes usinas a carvão do Brasil, a Energia Pecém (Pecém I de 720,27 MW e Pecém II com 365 MW). Conforme dados do IEMA (Instituto de Energia e Meio Ambiente), a captação de água realizada por essas termelétricas, localizada no porto do Pecém, a $60 \mathrm{~km}$ da capital cearense, é da ordem de $2.058 \mathrm{~m}^{3} /$ hora para Pecém I e $1.040,25 \mathrm{~m}^{3} /$ hora para Pecém II (IEMA, 2015). É necessário buscar outras fontes de energia limpa e renovável que substituam fontes de energia que utilizam combustíveis fósseis e o Ceará possui grande potencial eólico e solar.

O presente trabalho buscou uma forma de reduzir as emissões dos GEE sem deixar de atender a demanda de energia necessária para a sociedade. A solução proposta para essa problemática foi a instalação de usinas fotovoltaicas de grande porte em áreas classificadas como em processo de desertificação no município de Irauçuba, localizado no Ceará, com o objetivo de suprir a demanda de energia da termelétrica Pecém II e desliga-lá de forma parcial, no período de operação da usina fotovoltaica.

As áreas brasileiras mais vulneráveis às mudanças climáticas compreendem a Amazônia e o Nordeste (Guimarães et al., 2016). Além disso, o nordeste brasileiro é considerado vulnerável pelo fato de que as condições de aumento da temperatura e mudanças na precipitação podem transformar algumas áreas do território em regiões áridas e por se tratar da região semiárida mais povoada do mundo (Nóbrega, 2016).

$\mathrm{Na}$ busca pela redução de emissão dos GEE, é necessário estruturar a política da energia e do clima que contemple o trajeto econômico de cada país. Para qualquer ação que se decida tomar, o IPCC conclui que todos os cenários de estabilização climática indicam que boa parte da redução das emissões proverá de fontes de energia, de seu uso e de processos industriais, com a eficiência energética exercendo um papel chave em muitos cenários. Desse modo, dentro das três dimensões do desenvolvimento sustentável - ambiental, econômica e social -, a problemática energética apresenta grandes dificuldades, pois é necessária uma evolução dos modelos que demandem um consumo energético reduzido, com mais fontes renováveis e limpas na matriz elétrica e com mais investimentos nesse segmento. É essencial que as mudanças climáticas sejam integradas às políticas ambientais e de desenvolvimento, de modo que ações governamentais ajudem a enfrentar esse problema, avaliando a vulnerabilidade regional e nacional.

Conhecendo os elementos das mudanças climáticas e seus impactos ao longo da história, sabemos que serão mais severas em regiões vulneráveis, como é o caso do semiárido nordestino, que continua sendo afetado drasticamente com uma escassa estação chuvosa, um clima mais quente, um aumento das áreas em processo de desertificação, podendo alcançar situações irreversíveis. Nesse contexto, o presente trabalho objetiva contribuir na aplicação de medidas para desacelerar as mudanças climáticas, voltadas para a redução do tempo de operação de termelétricas, combatendo também o alto consumo de água no processo de geração de energia.

\section{Materiais e Métodos}

Foi realizado um estudo de caso no Complexo Porto do Pecém, especificamente para a unidade termelétrica Pecém II, de 365 MW. A solução apresentada no projeto é o desligamento parcial da Pecém II a partir da operação de uma grande usina fotovoltaica conectada diretamente à rede elétrica para suprir a demanda energética de Pecém II durante o período de insolação. Na pesquisa, foi escolhido o município de Irauçuba, no Ceará, pelo fato de possuir extensas áreas ideais para o empreendimento, ter boa irradiação solar e por ser estrategicamente próximo a uma linha de transmisão para a conexão elétrica com o sistema de potência.

Após a delimitação do tema, foi realizado um planejamento para execução da pesquisa, que incluiu revisão bibliográfica; coleta de dados de potência e captação de água da unidade Pecém II; verificar as linhas de financiamento existentes para a construção de usinas fotovoltaicas; identificar as liberações junto à Superintendência Estadual do Meio Ambiente (Semace); e conhecer as grandezas meteorológicas características de Irauçuba para o projeto da usina fotovoltaica.

$\mathrm{Na}$ pesquisa, foram adotadas as premissas afirmadas no âmbito científico e acadêmico: o aquecimento global está se intensificando e impactando em todos os sistemas climáticos, ameaçando o bem estar da sociedade e o meio 
ambiente. Boa parte desse processo é atribuída às atividades antrópicas em vários setores, porém limitou-se o trabalho ao setor de geração de energia elétrica na busca da redução da emissão de GEE.

No campo da geração de energia elétrica, foi realizada uma visita técnica ao Complexo Porto do Pecém, local de grandes plantas termelétricas da empresa Energia Pecém. Também foi realizada uma visita técnica ao eixo de integração de Sítios Novos e o Sistema portuário do Pecém, fonte de abastecimento de água do complexo portuário do Pecém e da termelétrica da Energia Pecém.

Além das visitas técnicas, foram coletados dados no sistema intranet da Chesf para obter dados de potência elétrica demandada por Pecém II, de corrente de operação da Linha de Transmissão (LT) de interligação e estruturas georreferenciadas que identificassem a linha de transmissão que cruzava por Irauçuba. A partir do histórico de medição da Chesf de Pecém II e da LT SBTPEDW1 durante o ano de 2017, foi possível obter o valor de potência média demandada pela termelétrica, o qual serviu de referência para o cálculo da capacidade instalada da usina fotovoltaica, como também o carregamento da LT existente para interligação elétrica.

A informação do volume da captação de água da termelétrica foi obtida a partir do histórico mensal do consumo de água fornecido estritamente pela Companhia de Gestão de Recursos Hídricos (Cogerh) no ano de 2017. Tendo o conhecimento da quantidade de horas que a termelétrica poderá ser desligada no dia, calculou-se a redução do volume de água mensal.

Para o projeto preliminar da usina fotovoltaica, fezse necessário identificar as grandezas meteorológicas, como radiação solar, insolação, temperatura ambiente do município de Irauçuba, sendo necessário o acesso ao Atlas Solarimétrico do Ceará, ao programa SunData (disponibilizado na página de internet do Centro de Referência para Energia Solar e Eólica Sérgio Brito - CRESESB), ao Atlas Brasileiro de Energia Solar e ao Atlas Solarimétrico do Brasil. Foi preciso, ainda, delimitar a localização da usina fotovoltaica, definir a inclinação dos módulos solares, calcular as perdas do sistema, definir o número total de módulos, a capacidade instalada e tensão elétrica de fornecimento. No dimensionamento do sistema fotovoltaico e dos custos envolvidos, por comparação com outras usinas fotovoltaicas já em operação, verificou-se que os resultados obtidos estavam coerentes para empreendimentos desse porte.

\section{Resultados e Discussão}

\subsection{Distribuição de frequência}

Com o desenvolvimento da pesquisa foi possível obter resultados de viabilidade técnica e econômica de um projeto preliminar de uma usina fotovoltaica em áreas sus- ceptíveis a desertificação. A Pecém II é situada em São Gonçalo do Amarante, e foi verificada a viabilidade de instalação da usina fotovoltaica em Irauçuba, ambos municípios localizados no estado do Ceará. Foi priorizado na pesquisa destacar os ganhos ambientais com a aplicação da respectiva proposta.

A partir de estudos realizados por pesquisadores das universidades e instituições estaduais, sendo uma delas a Fundação Cearense de Meteorologia e Recursos Hídricos (FUNCEME), foi possível obter o zoneamento geoecológico na área do núcleo de desertificação de Irauçuba/Centro-Norte, no Estado do Ceará (Funceme, 2015), onde foram mapeadas as áreas fortemente degradadas, em processo de desertificação, intensificadas pelas mudanças climáticas e atividades antrópicas. Essas áreas são as zonas fortemente degradadas e/ou desertificadas (ZFD) configuradas em núcleos de expansão nos Sertões de Irauçuba, caracterizadas por baixa diversidade biológica, alta diversidade ambiental, baixo estado de conservação e alta vulnerabilidade à erosão. Nesse mesmo município, observouse que $23,29 \%$ do seu território são ZFD, o que corresponde a $340,32 \mathrm{~km}^{2}$ (Funceme, 2015). A Fig. 1 delimita a ZFD para o Núcleo de Desertificação de Irauçuba/CentroNorte, sendo possível verificar a extensa ZFD de cor laranja existente no município de Irauçuba.

Na figura, identifica-se a ZFD em Irauçuba, que está próxima a uma rodovia asfaltada que cruza o município: a BR222. Após definir a localização para a usina, notou-se que a localização seria ideal, pois a LT SBTPEDW1 05V7 passa pelo respectivo terreno, paralelamente à BR222 e que conecta eletricamente a subestação PED (local de conexão com a termelétrica Pecém II) à subestação de SBT (localizada no município de Sobral), ambas da Chesf.

Para identificar as estruturas da respectiva LT que cruzam o município de Irauçuba, foi necessário acessar por meio do software de manutenção da Chesf as coordenadas geográficas da LT, através das quais foi possível visualizar no Google Earth, a disposição das estruturas na área selecionada. Também é importante conhecer o carregamento elétrico da LT, que apresenta a capacidade de condução dos cabos, para verificar a possibilidade de aumentar a corrente no circuito. Por isso, foi necessário obter dois relatórios no sistema corporativo da Chesf: um referente ao histórico de corrente da LT SBTPEDW1 05V7 e o outro sobre os limites operacionais desta, ambos disponibilizados pelo Centro Regional de Operação Norte (CRON).

A partir do Relatório de Limites Operacionais da subestação PED, o limite de corrente operacional da respectiva LT é de 2.956 ampères por fase (Chesf, 2017). A partir do histórico de corrente da LT SBTPEDW1, nos períodos de janeiro a outubro de 2017, também obtidos no site do CRON, foi calculada a média mensal e o registro do valor máximo mensal registrado nesse período. A Tabela 1 apresenta as respectivas médias mensais e carregamentos. 


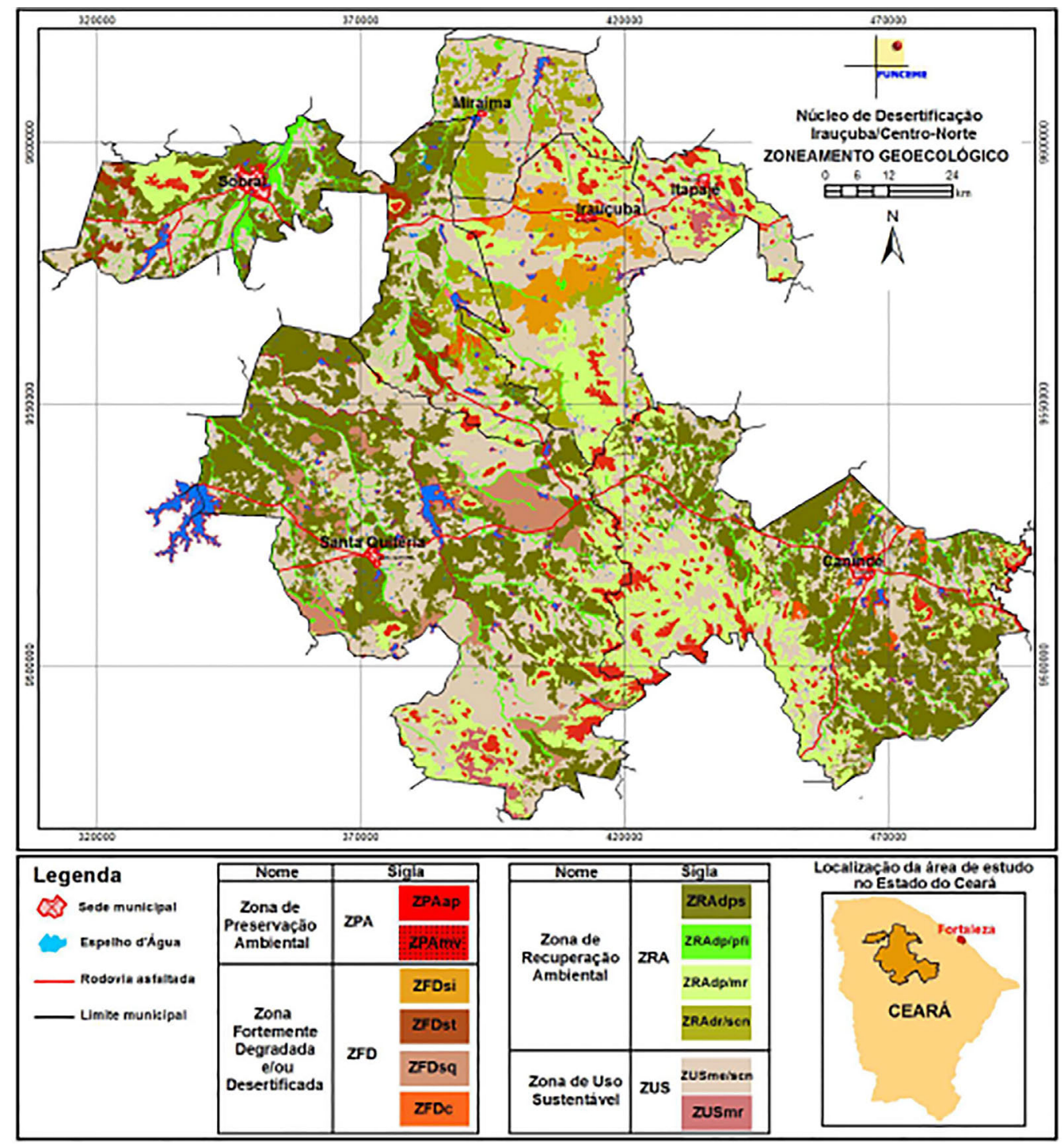

Figura 1 - Mapa do zoneamento geoecológico para o Núcleo de Desertificação de Irauçuba/Centro-Norte. Fonte: FUNCEME (2015).

Observou-se que o carregamento médio ficou em $11,50 \%$ e o máximo chegou a $21,37 \%$ no mês de setembro, ou seja, há muita ociosidade na LT. Como a potência demandada média $(S)$ da usina fotovoltaica é de 310 MVA, com uma tensão $(V)$ de $500 \mathrm{kV}$, então a corrente nominal fornecida pela usina fotovoltaica (Ifv) foi calculada conforme Eq. (1).

$$
\text { Ifv }=\frac{\mathrm{S}}{\sqrt{3} \cdot \mathrm{V}}=\frac{310(\mathrm{MVA})}{\sqrt{3} \cdot 500(\mathrm{kV})}=358,38 \mathrm{~A}
$$

Para a nova configuração, injetando a corrente nominal da usina fotovoltaica (Ifv) na LT SBTPEDW1, recalculou-se os carregamentos médio e máximo. Os novos valores obtidos são apresentados na Tabela 2.

O novo carregamento médio da LT SBTPEDW1 05V7 será de $23,63 \%$, com o máximo de $33,50 \%$ que foi registrado no mês de setembro, viabilizando tecnicamente a interligação.

\subsection{Potência elétrica fornecida pela usina fotovoltaica}

Para definir a capacidade instalada do gerador fotovoltaico, utilizou-se como referência a potência demandada pela termelétrica a partir do seu histórico de medição. Para o dimensionamento, considerou-se o rendimento global da planta fotovoltaica (módulo, inversores, entre outros). Posteriormente, obteve-se o histórico de potência demandada da Usina Pecém II no período de janeiro a outubro de 2017. Com base nesses dados, foi elaborada a Tabela $3 \mathrm{com}$ as médias mensais da potência reativa, potência ativa e potência aparente. Para os cálculos das médias, foram excluídas as medições horárias de valor zero. A tabela faz uma síntese dos valores médios mensais, bem como os valores máximos de potência registrados no perí- 
Tabela 1 - Dados de carregamento médio e máximo da LT SBTPEDW1 por fase no período de janeiro a outubro de 2017.

\begin{tabular}{lccccc}
\hline Meses & $\begin{array}{c}\text { Limite operacional da LV } \\
\text { 05V7 (A) }\end{array}$ & $\begin{array}{c}\text { Corrente média por } \\
\text { fase (A) }\end{array}$ & $\begin{array}{c}\text { Carregamento médio da LT } \\
\text { por fase (\%) }\end{array}$ & $\begin{array}{c}\text { Corrente máxima } \\
\text { por fase (A) }\end{array}$ & $\begin{array}{c}\text { Carregamento máximo da LT } \\
\text { por fase (\%) }\end{array}$ \\
\hline Jan./17 & 2956 & 325,44 & 11,01 & 569,58 & 19,27 \\
Fev./17 & 2956 & 359,87 & 12,17 & 509,717 & 17,24 \\
Mar./17 & 2956 & 375,18 & 12,69 & 467,82 & 15,83 \\
Abr./17 & 2956 & 346,97 & 11,74 & 475,09 & 16,07 \\
Mai./17 & 2956 & 344,81 & 11,66 & 443,28 & 15 \\
Jun./17 & 2956 & 327,87 & 11,09 & 479 & 16,2 \\
Jul./17 & 2956 & 294,39 & 9,96 & 484,65 & 16,4 \\
Ago./17 & 2956 & 354,36 & 11,99 & 563,24 & 19,05 \\
Set./17 & 2956 & 350,91 & 11,87 & 631,8 & 21,37 \\
Out./17 & 2956 & 320,11 & 10,83 & 479,27 & 16,21 \\
\hline
\end{tabular}

Fonte: Autoria própria a partir do histórico de leituras da Chesf (2017).

Tabela 2 - Carregamento médio e máximo (\%) da LT SBTPEDW1 com a inserção da usina fotovoltaica no circuito.

\begin{tabular}{|c|c|c|c|c|c|}
\hline Meses & $\begin{array}{l}\text { Limite operacional da LV } \\
\text { 05V7 (A) }\end{array}$ & $\begin{array}{l}\text { Corrente média por } \\
\text { fase }(\mathrm{A})\end{array}$ & $\begin{array}{c}\text { Carregamento médio da LT } \\
\text { por fase }(\%)\end{array}$ & $\begin{array}{l}\text { Corrente máxima } \\
\text { por fase }(\mathrm{A})\end{array}$ & $\begin{array}{c}\text { Carregamento máximo da LT } \\
\text { por fase }(\%)\end{array}$ \\
\hline Jan./17 & 2956 & 683,82 & 23,13 & 927,96 & 31,39 \\
\hline Fev./17 & 2956 & 718,25 & 24,3 & 868,097 & 29,37 \\
\hline Mar./17 & 2956 & 733,56 & 24,82 & 826,2 & 27,95 \\
\hline Abr./17 & 2956 & 705,35 & 23,86 & 833,47 & 28,2 \\
\hline Mai./17 & 2956 & 703,19 & 23,79 & 801,66 & 27,12 \\
\hline Jun./17 & 2956 & 686,25 & 23,22 & 837,38 & 28,33 \\
\hline Jul./17 & 2956 & 652,77 & 22,08 & 843,03 & 28,52 \\
\hline Ago./17 & 2956 & 712,74 & 24,11 & 921,62 & 31,18 \\
\hline Set./17 & 2956 & 709,29 & 23,99 & 990,18 & 33,5 \\
\hline Out./17 & 2956 & 678,49 & 22,95 & 837,65 & 28,34 \\
\hline
\end{tabular}

Fonte: Autoria própria a partir de dados da Chesf(2017).

odo de análise. A potência ativa aparece com o sinal negativo por definição, por se tratar de uma fonte de energia.

A partir dos dados de potência de Pecém II, apresentados na Tabela 3, a usina fotovoltaica foi projetada para atender a potência aparente média de 215,04 MVA (média aritmética das potências aparente dos meses de janeiro a outubro de 2017), como também a potência aparente máxima de 308,23 MVA. A potência elétrica total ou aparente (unidade em MVA) é composta de duas parcelas, a potência ativa (unidade em watts) e a potência reativa (unidade em VAr), sendo a razão entre a potência ativa $(P)$ e a potência aparente $(S)$ denominada de fator de potência $(F P)$ apresentada na Eq. (2).

$$
F P=\frac{P(M W)}{S(M V A)}
$$

Dessa forma, a base de cálculo da capacidade instalada do gerador fotovoltaico é a mesma potência fornecida pela termelétrica para o Sistema Interligado Nacional (SIN), sendo o valor definido em 310 MVA, um pouco superior ao valor máximo registrado do seu histórico. Com os da- dos da Tabela 3, pôde-se determinar o fator de potência: para a Usina Pecém II, o fator de potência médio foi de 0,95 (indutivo médio). Conhecendo o fator de potência e a potência aparente, pôde-se aplicar a Eq. (3) para conhecer a potência ativa:

$$
P=F P \times S=294,5 \mathrm{MW}
$$

\subsection{Inclinação dos módulos fotovoltaicos, radiação solar e temperatura em Irauçuba}

Para evitar o acúmulo de sujeira na superfície dos módulos, adotou-se um ângulo de inclinação de $10^{\circ}$ com o plano horizontal. A Tabela 4 apresenta os valores de Irradiação solar diária média mensal (Irrad) analisados no período de 1999 a 2015 e a correção desses dados (Irradk) de acordo com a Tabela de Fatores de Correção da Radiação para Superfícies Inclinadas, que informa o fator de correção (k). A média de irradiação solar no ano será a média aritmética dos valores mensais já corrigidos pelo fator $\mathrm{k}$, ou seja, $5,49 \mathrm{kWh} / \mathrm{m}^{2}$.dia. 
Tabela 3 - Carregamento médio e máximo (\%) da LT SBTPEDW1 com a inserção da usina fotovoltaica no circuito.

\begin{tabular}{lccccc}
\hline Período & $\begin{array}{c}\text { Potência reativa média } \\
\text { mensal (MVAr) }\end{array}$ & $\begin{array}{c}\text { Potência ativa média } \\
\text { mensal (MW) }\end{array}$ & $\begin{array}{c}\text { Potência aparente média } \\
\text { mensal (MVA) }\end{array}$ & $\begin{array}{c}\text { Potência reativa máxima } \\
\text { mensal (MVAr) }\end{array}$ & $\begin{array}{c}\text { Potência aparente máxima } \\
\text { mensal (MVA) }\end{array}$ \\
\hline Jan./17 & 63,12 & $-187,66$ & 198,43 & 268,19 & 106,25 \\
Fev./17 & 64,33 & $-191,57$ & 202,08 & 272,12 & 128,62 \\
Mar./17 & 59,58 & $-206,91$ & 215,67 & 266,94 & 113,92 \\
Abr./17 & 66,52 & $-223,83$ & 234,23 & 278,64 & 131,77 \\
Mai./17 & 70,02 & $-221,51$ & 232,92 & 264,73 & 114,95 \\
Jun./17 & 65,13 & $-184,45$ & 196,18 & 271,99 & 120,31 \\
Jul./17 & 59,4 & $-166,96$ & 177,36 & 176,2 & 75,24 \\
Ago./17 & 61,92 & $-215,19$ & 224,31 & 268,26 & 106,93 \\
Set./17 & 67,63 & $-226,13$ & 236,31 & 278,97 & 121,73 \\
Out./17 & 69,76 & $-242,46$ & 252,49 & 269,1 & 114,88 \\
\hline
\end{tabular}

Fonte: Autoria própria a partir do histórico de leituras da Chesf (2017).

Tabela 4 - Dados de radiação solar no município de Irauçuba.

\begin{tabular}{lcccccccccccc}
\hline Mês & Jan & Fev & Mar & Abr & Jun & Jul & Ago & Set & Out & Nov & Dez & Média \\
\hline Irrad & 5,2 & 5,32 & 5,19 & 4,78 & 4,97 & 5,01 & 5,32 & 6,08 & 6,52 & 6,43 & 6,22 & 5,62 \\
Fator k & 0,93 & 0,96 & 0,99 & 1,03 & 1,05 & 1,05 & 1,04 & 1,02 & 0,99 & 0,96 & 0,94 & 0,93 \\
Irradk & 4,84 & 5,11 & 5,14 & 4,92 & 5,22 & 5,26 & 5,53 & 6,2 & 6,45 & 6,17 & 5,85 & 5,23 \\
\hline
\end{tabular}

Fonte: Adaptado de CRESESB (2017).

Os coeficientes de temperatura dos módulos fotovoltaicos tomam como base as suas características elétricas em Condições Padrões de Ensaio (STC - do inglês Standard Test Conditions), com a temperatura das células fotovoltaicas no valor padrão de $25{ }^{\circ} \mathrm{C}$. Qualquer valor acima ou abaixo dessa referência significa alterações nos valores das características elétricas dos módulos, resultando numa perda de geração de energia elétrica. Vale destacar que a região de análise possui uma temperatura média acima do valor de referência e se faz necessário obter a temperatura média do ar local para recalcular a potência pico final do módulo. Foi considerada a média de temperatura máxima registrada no município de Sobral, pois não há registros para Irauçuba na base de dados do INMET. A Tabela 5 apresenta a média anual de temperatura máxima nesse período.

Para recalcular a potência pico final do módulo, será a média das temperaturas máximas, $33,5{ }^{\circ} \mathrm{C}$ como sendo a temperatura ambiente local.

\subsection{Viabilidade técnica e econômica}

Optou-se por um módulo com alta potência de pico (Wp) e com isolamento de $1500 \mathrm{Vdc}$. A partir do data- sheet do fabricante selecionado, a Tabela 6 apresenta os alguns dados técnicos do módulo.

Como a potência de saída já é conhecida, estimou-se as perdas do sistema fotovoltaico para dimensionar a potência instalada do gerador fotovoltaico a fim de garantir a potência de saída esperada, compensando todas as perdas da planta. Os coeficientes de perda do sistema fotovoltaico são estimados na Tabela 7.

Na Tabela 7 foram listados os valores adotados para o cálculo das perdas de forma setorial. A seguir é apresentado o cálculo do fator temperatura (Ktemp). Para se obter a diferença entre as grandezas elétricas em condições de laboratório e as estimativas dessas características em campo, deve-se multiplicar a temperatura ambiente pelo coeficiente de temperatura fornecido pelo fabricante no datasheet e aplicar na Eq. (4):

$$
\text { Ktemp }=T \times C t e m p
$$

onde Ktemp é a diferença entre as características elétricas em STC e a estimativa de característica elétrica em campo; $T$ é a média anual das temperaturas máximas $\left({ }^{\circ} \mathrm{C}\right)$ apresentada na Tabela 5; e Ctemp é o coeficiente de tem-

Tabela 5 - Média de temperatura mensal e anual consideradas para o município de Irauçuba.

\begin{tabular}{lccccccccccccc}
\hline Média & Jan & Fev & Mar & Abr & Jun & Jul & Ago & Set & Out & Nov & Dez & Anual \\
\hline Temperatura & 33,8 & 32,3 & 31,4 & 31,1 & 31,2 & 31,6 & 33 & 34,8 & 35,8 & 35,9 & 35,6 & 35,5 \\
\hline
\end{tabular}

Fonte: INMET (2017). 
Tabela 6 - Carregamento médio e máximo (\%) da LT SBTPEDW1 com a inserção da usina fotovoltaica no circuito.

\begin{tabular}{|c|c|}
\hline Fabricante & CanadianSolar \\
\hline Modelo & DIAMOND CS6X-320P-FG \\
\hline Tipo & Silício policristalino \\
\hline Rendimento & 25 anos $-85,5 \%$ \\
\hline Arranjo & 72 células \\
\hline Dimensões & $1968 \times 992 \times 5,8 \mathrm{~mm}$ \\
\hline Potência (Pmax) & $320 \mathrm{Wp}$ \\
\hline $\mathrm{Vmp}$ & $36,8 \mathrm{~V}$ \\
\hline $\operatorname{Imp}$ & $8,69 \mathrm{~A}$ \\
\hline Tensão de Circuito Aberto (Vop) & $45,3 \mathrm{~V}$ \\
\hline Corrente de Curto Circuito (Isc) & $9,26 \mathrm{~A}$ \\
\hline Eficiência & $16,39 \%$ \\
\hline Temperatura de operação & $(-) 40^{\circ} \mathrm{C}$ até $+85^{\circ} \mathrm{C}$ \\
\hline Max. System Voltage & 1500 (IEC) or $1000 \mathrm{~V}$ (UL) \\
\hline Máximo fusível em série & $15 \mathrm{~A}$ \\
\hline Power Tolerance & $0 \sim+5 \mathrm{~W}$ \\
\hline Temperature Coefficient (Pmax) & $(-) 0.41 \% /{ }^{\circ} \mathrm{C}$ \\
\hline Temperature Coefficient (Voc) & $(-) 0.31 \% /{ }^{\circ} \mathrm{C}$ \\
\hline Temperature Coefficient (Isc) & $0.053 \% /{ }^{\circ} \mathrm{C}$ \\
\hline $\begin{array}{l}\text { Temperatura nominal de operação } \\
\text { da célula }\end{array}$ & $45 \pm 2{ }^{\circ} \mathrm{C}$ \\
\hline
\end{tabular}

Fonte: Datasheet do módulo DIAMOND $320 \mathrm{Wp}$ do fabricante CanadianSolar, 2017.

Tabela 7 - Coeficientes de perda estimados setorialmente.

\begin{tabular}{lcc}
\hline Coeficiente de perda & Símbolo & Valor considerado \\
\hline Sombreamento & Ksomb & $5 \%$ \\
Sujeira & Ksuj & $2 \%$ \\
Tolerância de potência & Ktol & $0 \%$ \\
Mistmatching & Kmis & $2 \%$ \\
Fator Temperatura & Ktemp & $13,73 \%$ \\
Cabeamento CC & Kcc & $1 \%$ \\
SPMP & Kspmp & $2 \%$ \\
Conversão CC/CA & Kinv & $5 \%$ \\
Cabeamento CA & Kca & $1 \%$ \\
\hline
\end{tabular}

Fonte: Adaptado do DSG (2013).

peratura para a característica elétrica a ser compensada (\%) por grau (fornecido pelo fabricante).

Aplicando as variáveis $T=33,5{ }^{\circ} \mathrm{C}$ e Ctemp $=$ $-0,41 \% /{ }^{\circ} \mathrm{C}$, temos da Eq. (4) que Ktemp $=-13,73 \%$. A equação da diferença de características elétricas resultará em um valor percentual de rendimento por fator temperatura que deverá ser adicionado à grandeza elétrica em STC do módulo fotovoltaico, conforme a Eq. (5), onde $R^{\circ} \mathrm{C}$ é a estimativa de rendimento da grandeza elétrica do módulo fotovoltaico (\%). Aplicando o valor de Ktemp na Eq. (5), tem-se que $R^{\circ} \mathrm{C}=86,26 \%$.

$$
R^{\circ} \mathrm{C}=1+\text { Ktemp }
$$

Posteriormente, calcula-se a estimativa de potência-pico do módulo fotovoltaico corrigido para a nova temperatura de trabalho, utilizando o valor da potência-pico em condições de laboratório (STC), $320 \mathrm{Wp}$, multiplicando pelo valor de $R^{\circ} \mathrm{C}$. O valor final será $276,03 \mathrm{Wp}$, sendo o seu rendimento de $86,26 \%$ e perda de $13,73 \%$ para o fator temperatura Ktemp. Conhecendo os fatores de perda da Tabela 7, calcula-se o rendimento global do sistema fotovoltaico através da multiplicação de todos esses coeficientes em decimal de acordo com a Tabela 8.

A partir dos coeficientes de perda já contabilizados na forma decimal apresentada na Tabela 7 , aplica-se na Eq. (6) para o Rendimento Global $\left(R_{g}\right)$.

$$
\begin{array}{r}
R_{g}=C s o m b \times C s u j \times C t o l \times C m i s \\
\times C t e m p \times C c c \times C s p m p \times C i n v \times C c a
\end{array}
$$

E então $R_{g}=71,81 \%$. Com o valor do rendimento global determinado, pode-se determinar as perdas $(P)$ pela Eq. (7), de onde se conclui que $P=28,19 \%$ :

$$
P=1-R_{g}
$$

Para suprir as perdas do sistema fotovoltaico (em torno de $28,19 \%$ ) e a degradação dos módulos durante 25 anos, a potência fornecida ao sistema elétrico terá que ser no mínimo 294,5 MW para garantir o atendimento das cargas alimentadas pela termelétrica Pecém II. Assim, a capacidade instalada da usina fotovoltaica será em torno de $430 \mathrm{MW}$ (valor adotado) para contabilizar $28,19 \%$ de perdas, sendo a potência fornecida ao sistema elétrico de 308,78 MW.

Para calcular a quantidade de módulos necessários para gerar a potência esperada na saída do sistema fotovoltaico, utilizou-se as Eqs. (8), (9) e (10). A energia elétrica fornecida pela usina diariamente $\left(E_{f}\right)$ é dada pelo produto da potência do gerador pelo tempo de insolação, apresentado na Eq. (7).

Tabela 8 - Valores dos coeficientes de rednimento aplicados na equação de rendimento global.

\begin{tabular}{lcc}
\hline Coeficiente de rendimento & Símbolo & Valores em \% \\
\hline Sombreamento & Csomb & 0,95 \\
Sujeira & Csuj & 0,98 \\
Tolerância de Potência & Ctol & 1 \\
Mismatching & Cmis & 0,98 \\
Cabeamento CC & Ccc & 0,99 \\
Fator Temperatura & Ctemp & 0,8626 \\
SPMP & Cspmp & 0,98 \\
Conversão CC/CA & Cinv & 0,95 \\
Cabeamento CA & Cca & 0,99
\end{tabular}




$$
E_{f}=\left(4,3 \times 10^{5}\right) \mathrm{kW} \times 7 \frac{\mathrm{h}}{\mathrm{dia}}=3,01 \times 10^{6} \mathrm{~kW} / \mathrm{dia}(8)
$$

Para converter a potência elétrica em potência pico (Ppico), foi aplicada a Eq. (8), através da razão entre $E_{f}$ e a média da irradiação solar corrigida pelo fator $\mathrm{k}(5,49 \mathrm{kWh} /$ $\mathrm{m}^{2}$.dia).

$$
P_{\text {pico }}=\frac{3.010 .000}{5,49}=548.269,58 \mathrm{kWp}
$$

Por fim, para se obter o número $(n)$ de módulos necessários, aplicou-se a Eq. (9), sendo a razão entre $P_{\text {pico }}$ em watts e a potência nominal do módulo de $320 \mathrm{Wp}$.

$$
n=\frac{548.269,58}{320} \times 1000=1.713 .343
$$

O inversor atua como localizador automático do ponto de máxima potência dos módulos, visando maximizar a eficiência, como também converte o circuito em corrente contínua para corrente alternada, sendo a tensão elétrica com magnitude e frequência idêntica ao da rede. Além de monitorar as grandezas elétricas, já vem com funções de proteção (sobrecorrente, sobretensão, subtensão, subfrequência, detecção de falta a terra), como também realizam a correção do fator de potência da rede, com o controle de reativos, a proteção conta todas as falhas de energia, regulação de tensão e correção de harmônicos. O projeto inclui a instalação de 68 estações de inversores ABB PVS980MWS, cada uma com capacidade de 4,6 MW. Cada estação, abriga dois inversores, um transformador BT/MT, sistemas auxiliares de potência auxiliar, monitoramento, filtração de ar, entre outros.

Para atestar a viabilidade econômica, foram utilizadas as ferramentas financeiras: Valor Presente Líquido (VPL), payback e Taxa Interna de Retorno (TIR). O investimento necessário seria de $\mathrm{R} \$ 5.133 .939 .095,52$, com boa parte do montante financiado pelo Bando Nacional de Desenvolvimento (BNDES). O projeto se mostrou viável com um lucro no final de 30 anos de R \$ 1.464.922.015,69. Sendo o tempo de retorno, o payback descontado, no início do vigésimo quarto ano de operação da usina fotovoltaica. A TIR foi de 5\% a.a.

\subsection{Aspectos ambientais}

O carvão é o mais abundante dos combustíveis fósseis e também o maior emissor de GEE. Atende 11,5\% do consumo de energia no mundo e é responsável por cerca de $46 \%$ das emissões globais. No Brasil, a exploração das poucas reservas de carvão concentra-se em Santa Catarina e no Rio Grande do Sul. As usinas termelétricas a carvão têm participação de 4,3\% na matriz elétrica atual, sendo no Ceará a maior delas, a Energia Pecém (Greenpeace, 2016).
As termelétricas a carvão mineral são as campeãs no ranking de emissão, sendo os valores mínimos de $800 \mathrm{~g}$ de $\mathrm{CO}_{2} / \mathrm{kWh}$ (Greenpeace, 2010). Para a térmica Pecém II, a partir da média dos dados da coluna "Potência Ativa Média Mensal (MW)" na Tabela 3, sua demanda média mensal é 206,67 MW e considerando o seu desligamento no período de funcionamento da usina fotovoltaica no período de insolação ( 7 horas), sendo a energia ofertada pela termelétrica por dia corresponde a $1.446,69 \mathrm{MWh}$ e no mês 43.400,70 MWh. Então a redução de emissão de $\mathrm{CO}_{2}$ para a atmosfera com o desligamento parcial da termelétrica durante sete horas por dia, será de 1.157,35 toneladas de $\mathrm{CO}_{2}$ por dia e no mês $34.720,56$ toneladas de $\mathrm{CO}_{2}$.

As termelétricas a carvão utilizam como ciclo de potência o de Rankine, a vapor, que é o ciclo de potência básico utilizado na grande maioria das usinas termelétricas em operação no mundo (IEMA, 2015). Além de se utilizar a água em forma de vapor para girar a turbina do gerador e assim gerar eletricidade, é necessário um grande volume de água para o processo de "resfriamento do vapor" - através dos condensadores e torres de resfriamento- retornando para o estado líquido para iniciar um novo ciclo.

Dessa forma, para quantificar a captação de água da Pecém II, foi necessário acessar os dados de consumo de água em metros cúbicos $\left(\mathrm{m}^{3}\right)$ no período de dezembro/ 2016 a setembro de 2017, disponilibilizados pela Companhia de Gestão dos Recursos Hídricos (Cogerh), através de um ofício solicitado pela Universidade Estadual do Ceará (UECE), foi possível estimar a economia de água com o desligamento parcial da termelétrica Pecém II por sete horas. A Tabela 9 apresenta o consumo de água $\left(\mathrm{m}^{3}\right)$ mensal no período de dezembro de 2016 a setembro de 2017, faturado pela Cogerh, da empresa Energia Pecém (Pecém I e Pecém II), sendo o seu nome na fatura especificado como Porto do Pecém geração de Energia SA.

A partir da Tabela 9, o valor de captação de água $\left(\mathrm{m}^{3}\right)$ médio é $1.292 .305,39$, obtido a partir da média dos dados da coluna "Consumo $\left(\mathrm{m}^{3}\right)$ ". Para obter o consumo de água por hora $\left(\mathrm{m}^{3} / \mathrm{h}\right)$, dividiu-se o consumo mensal pela quantidade de horas num mês $(24 \mathrm{~h} \times 30=720 \mathrm{~h})$. Posteriormente, foi realizada uma média dos valores de consumo $\left(\mathrm{m}^{3} / \mathrm{h}\right)$ dos dez meses do período, sendo o resultado $1.770,19 \mathrm{~m}^{3} / \mathrm{h}$. Para se chegar no valor aproximado de captação de água $\left(\mathrm{m}^{3} / \mathrm{h}\right)$ somente da Pecém II, foi utilizado o método da porporcionalidade a partir dos dados nominais do sua vazão informados pelo Instituto de Energia e Meio Ambiente IEMA. Os dados nominais da captação de água $\mathrm{em} \mathrm{m}^{3} / \mathrm{h}$ da Pecém I e Pecém II são respectivamente $2.052,78 \mathrm{~m}^{3} / \mathrm{h}$ e $1.040,25 \mathrm{~m}^{3} / \mathrm{h}$, ou seja, o consumo de Pecém II representa $33,63 \%$ da vazão total $\left(\mathrm{m}^{3} / \mathrm{h}\right)$, com $595,31 \mathrm{~m}^{3} / \mathrm{h}$. Considerando o seu desligamento durante o período de 7 horas por dia, com o funcionamento da usina fotovoltaica, então teremos uma redução no volume de $4.167,20 \mathrm{~m}^{3}$ por dia e no mês representaria 
Tabela 9 - Histórico de consumo de água mensal $\left(\mathrm{m}^{3}\right)$ da empresa Energia Pecém (Termelétricas Pecém I e II) no período de Dezembro de 2016 a Setembro de 2017.

\begin{tabular}{lc}
\hline Coeficiente de rendimento & Símbolo \\
\hline $1.055 .252,00$ & $1.418,35$ \\
$1.278 .705,00$ & $1.718,69$ \\
$1.058 .324,89$ & $1.574,89$ \\
$1.436 .991,00$ & $1.931,44$ \\
$1.507 .179,00$ & $2.093,30$ \\
$1.487 .447,00$ & $1.999,26$ \\
$1.160 .400,00$ & $1.611,67$ \\
$1.138 .711,00$ & $1.530,53$ \\
$1.454,587,00$ & $1.955,09$ \\
$1.345 .457,00$ & $1.868,69$
\end{tabular}

Fonte: Adaptado de Cogerh (2017).

uma redução de $125.016,13 \mathrm{~m}^{3}$, ou seja, uma redução de $9,67 \%$ do volume de captação de água por mês no açude Sítios Novos.

Dessa forma, se a termelétrica a carvão Pecém II for acionada apenas nos períodos de baixa geração de energia elétrica da usina fotovoltaica (horários noturnos, dias nublados e com chuva), a estimativa do ganho ambiental, com o seu desligamento durante 7 horas por dia, será a redução da emissão de didóxido de carbono em 34.720,56 toneladas por mês e da captação de água em $125.016,20 \mathrm{~m}^{3}$ por mês, ou seja, uma redução de $9,67 \%$ do volume de captação de água no mês. Um outro ponto a se destacar é a vantagem do empreendimento em questão, aproveitar uma linha de transmissão já existente para a conexão elétrica com o SIN, evitando os impactos socioambientais associadas à sua construção e manutenção.

\section{Considerações Finais}

A solução técnica apresentada na pesquisa é investir em usinas fotovoltaicas conectadas à rede elétrica no Ceará, em virtude de seu grande potencial solar disponível, para substituir parcialmente as termelétricas a carvão do estado. Dessa forma, foi realizado um estudo de caso para o desligamento parcial da termelétrica Pecém II, no município de São Gonçalo do Amarante, com a instalação de uma usina fotovoltaica de capacidade instalada equivalente, no Município de Irauçuba, aproveitando áreas susceptíveis à desertificação.

O projeto da usina fotovoltaica em Irauçuba se apresentou viável tecnicamente e economicamente, com impactos ambientais bem reduzidos quanto à instalação, uma vez que na fase de instalação não seria necessário construir extensas linhas de transmissão essenciais. Isso se deve ao fato de que próximo às áreas disponíveis existe uma LT de $500 \mathrm{kV}$ conectando a subestação do acessante Pecém II com a subestação no município de Sobral e será o meio de conexão elétrica com o SIN.
Para o setor elétrico, o ganho seria o aumento da participação da fonte solar na matriz elétrica cearense e o incentivo a investimentos locais nesse segmento. Nos aspectos ambientais a pesquisa apresentou três aspectos importantes relacionados à mitigação dos efeitos do processo de mudanças climáticas. O primeiro deles é a utilização de áreas que, devido às causas naturais e antrópicas, concorrem para um estágio avançado de desertificação. $\mathrm{O}$ segundo está relacionado à escassez de recursos hídricos, os quais são bastante demandados na termelétrica ao passo que, na geração fotovoltaica, o seu uso é praticamente similar ao uso residencial. Por fim, a emissão de GEE sofre uma significativa redução por conta do desligamento da termelétrica.

Percebe-se ao longo deste trabalho que, no setor elétrico, especificamente olhando para o ONS, faltou priorizar em suas estratégias de operação e controle do SIN métodos que assegurem e priorizem fontes de geração de energia limpa e renovável em detrimento das fontes que emitem GEE. A pesquisa desenvolvida para o estado do Ceará pode ser replicada para outras regiões do Brasil, sobretudo para o Nordeste. O processo de desativação de termelétricas e a inserção de fontes de energias renováveis e limpas é uma opção não somente ambiental e econômica, mas também política. Portanto, defendemos que os pontos aqui defendidos permeiem o planejamento energético sob todos esses pontos de vista.

Há de ressalvar que por depender de um recurso natural, a geração fotovoltaica é intermitente, ou seja, há períodos do dia ou do ano que a energia gerada pode ser tão baixa que não atenda a demanda requerida. Nessas situações, no caso da geração hídraúlica não atender, é preciso que se recorra às termelétricas, por isso não defendemos aqui a desativação total destas. Defende-se, no entanto, seu uso mínimo em situações estritamente emergenciais para o suprimento de faltas.

\section{Referências}

CENTRO DE REFERÊNCIA PARA ENERGIA SOLAR E EÓLICA - CRESESB. Radiação Solar. Disponível em http:// www.cresesb.cepel.br/index.php?section=com_conten t\&lang=pt\&cid=301. Acesso em 11 out. 2017.

COGERH. Disponível em <www.cogerh.com.br\&gt;. Acesso em 07 fev. 2017.

COMPANHIA HIDRO ELÉTRICA DO SÃO FRANCISCO CHESF. Intranet. Disponível em http://10.136.60.10/proje tosWeb/SupervisionWeb/index.php?link=pas-menu.php. Acesso em 10 out. 2017.

DATASHEET CANADIAN SOLAR. Disponível em https:// www.canadiansolar.com/downloads/datasheets/na/Cana dian_Solar-Datasheet-CS6XPFG_Diamond-v5.3_na.pdf. Acesso em 12 out. 2017.

DRUMM, F.C.; GERHARDT, A.E.; FERNANDES, G.D.; CHAGAS, P.; SUCOLOTTI, M.S.; et al. Poluição atmosférica proveniente da queima de combustíveis derivados do 
petróleo em veículos automotores. Revista Eletrônica em Gestão, Educação e Tecnologia Ambiental, v. 18 n. 1, p. 66-78, 2014.

FUNDAÇÃO CEARENSE DE METEOROLOGIA E RECURSOS HÍDRICOS - FUNCEME. Zoneamento EcológicoEconômico das Áreas Susceptíveis à Desertificação do Núcleo II - Inhamuns. Fortaleza: Departamento Nacional de Obras Contra as Secas, 2015.

DSG - GERMAN SOLAR ENERGY SOCIETY. Planning and Installing Photovoltaic Systems. 3rd Ed., New York: Routledge Press, 2013.

GREENPEACE. A Caminho do Desenvolvimento Limpo. Dados do Greenpeace. dez. 2016. Disponível em http:// www.greenpeace.org/brasil/Global/brasil/image/2015/ Dezembro/2016/Revolução\%20Energética\%202016.\% 20Greenpeace\%20Brasil.pdf. Acesso em 17 out. 2017.

GUIMARÃES, S.O.; COSTA, A.A.; VASCONCELOS JÚNIOR, F.C.; SILVA, E.M.; SALES, D.C.; ARAÚJO JÚNIOR, L.M.; SOUZA, S.G. Projeções de mudanças climáticas sobre o Nordeste brasileiro dos modelos do CMIP5 e do CORDEX. Revista Brasileira de Meteorologia, v. 31, n. 3, p.1-36, 2016.

INSTITUTO DE ENERGIA E MEIO AMBIENTE - IEMA. Série Termoeletricidade em Foco: Uso de Água em Termoelétricas, 2016. Disponível em http://www.energiaeam biente.org.br/wp-content/uploads/2016/11/IEMA-AGUA. pdf. Acesso em 1 set. 2017.

INSTITUTO NACIONAL DE METEOROLOGIA - INMET. Normais Climatológicas do Brasil 1961-1990. Disponível em http://www.inmet.gov.br/portal/index.php?r=clima/nor maisClimatologicas. Acesso em 11 out. 2017.

INTERGOVERNMENTAL PANEL ON CLIMATE CHANGE IPCC. Climate Change 2013: The Physical Science Basis. Contribution of Working Group I to the Fifth
Assessment Report of the Intergovernmental Panel on Climate Change. STOCKER, T.F.; QIN, D.; PLATTNER, G.-K.; TIGNOR, M.; ALLEN, S.K.; BOSCHUNG, J.; NAUELS, A. et al. (eds) Cambridge University Press, Cambridge, $1585 \mathrm{pp}$.

NASCIMENTO, R.S.; ALVES, G.M. Fontes alternativas e renováveis de energia no Brasil: Métodos e benefícios ambientais. XX Encontro Latino Americano de Iniciação Científica, XVI Encontro Latino Americano de PósGraduação e VI Encontro de Iniciação à Docência. Universidade do Vale do Paraíba, 2016.

NÓBREGA, R.S. Tendências do controle climático oceânico sob a variabilidade temporal da precipitação no Nordeste do Brasil. Revista de Geografia Norte Grande, n. 63, p. 134, 2016.

OLIVEIRA, G.S. Mudanças climáticas: ensino fundamental e médio. Coleção Explorando o Ensino, v. 13. Brasília: $\mathrm{MEC} / \mathrm{SEB} / \mathrm{MCT} / \mathrm{AEB}, 2009$.

ONS - OPERADOR NACIONAL DO SISTEMA ELETRÔNICO. Histórico da operação. 2017. Disponível em: http://ons.org.br/Paginas/resultados-da-operacao/historicoda-operacao/geracao_energia.aspx. Acesso em 1 set. 2017.

TILIO NETO, P. Ecopolítica das Mudanças Climáticas: O IPCC e o Ecologismo dos Pobres [online]. Rio de Janeiro: Centro Edelstein de Pesquisas Sociais, 2010. Available from SciELO Books http://www.scielo.br/scielo.php? script $=$ sci_arttext\&pid=S0102$77862016000700337 \& \operatorname{lng}=$ en\&nrm $=$ iso\&tlng=pt. Acesso em 13 fev. 2017.

License information: This is an open-access article distributed under the terms of the Creative Commons Attribution License (type CC-BY), which permits unrestricted use, distribution and reproduction in any medium, provided the original article is properly cited. 